\title{
Penyajian Musik Antar-antaran Pada Acara Pernikahan Di Desa Penanggoan Duren Kecamatan Tulung Selapan Kabupaten Ogan Komering Ilir
}

\author{
Deria Sepdwiko ${ }^{1)}$ \\ Program Studi Seni Pertunjukan Universitas PGRI Palembang \\ Jl. Jend. A. Yani. Lrg. Gotong Royong 9/10 Ulu Palembang \\ Email: sepdwiko.deria@gmail.com ${ }^{l)}$
}

\begin{abstract}
This study formulates the problem of how the form of music presentation in delivery at weddings in Penanggoan Duren Village, Tulung Selapan District, Ogan Komering Ilir Regency. This study aims to determine how the form of music presentation in, delivery at weddings in the village of Penanggoan Duren. This research is qualitative. Data collection techniques include observation, interviews, and documentation. The results showed that this delivery was only carried out when the bride and groom came from the same village, this was because the distance was far in the process of walking, and this delivery only used kenong and tambourine instruments as media accompaniment. intermediate. The wasp pattern in kenong has 1 pattern that is usually played, then the tambourine has a wasp pattern, namely wasps 1, 2, 3, and 4. The art of inter-delivery music which has become a basic need for the community of Penanggoan Duren village, Tulung Selapan sub-district, Ogan Komering Ilir district as a special media for accompaniment and entertainers who are always used in delivery at weddings. Inter-delivery is a traditional art in the village of Penanggoan Duren, which is a walking process carried out by the groom to the bride's house by bringing an offering to be given to the bride without a unilateral agreement. In the form of foodstuffs such as rice, chicken, spices, areca nut trees, bananas and many more.
\end{abstract}

Keywords : Presentation, Music in Inter-delivery, Penggoan Duren Villa

\begin{abstract}
ABSTRAK
Penelitian ini merumuskan masalah bagaimana bentuk penyajian musik dalam antar-antaran pada acara pernikahan di desa Penanggoan Duren Kecamatan Tulung Selapan kabupaten Ogan Komering Ilir. Penelitian ini bertujuan untuk mengetahui bagaimana penyajian musik dalam antar-antaran pada acara pernikahan yang berada pada desa Penanggoan Duren. Penelitian ini menggunakan metode kualitatif. Teknik pengumpulan data meliputi observasi, wawancara, dan dokumentasi. Hasil penelitian menunjukan bahwa antar-antaran ini hanya dilakukan pada saat mempelai laki-laki dan perempuan berasal dari desa yang sama hal ini dikarenakan jauh nya jalan tempuh dalam proses berjalan kaki, dan antar-antaran ini hanya menggunakan alat musik kenong dan rebana srebagai media mengiring antar-antaran. Pola tabuhan dalam kenong terdapat 1 pola yang biasanya dimainkan, selanjutnya rebana memiliki pola tabuhan yaitu tabuhan 1, 2, 3, dan 4. Kesenian musik antar-antaran yang sudah menjadi kebutuhan pokok bagi kalangan masyarakat desa penanggoan duren kecamatan tulung selapan kabupaten ogan komering ilir sebagai khusus media pengiring dan penghibur yang selalu digunakan dalam antar-antaran pada acara pernikahan. Antar-antaran merupakan suatu kesenian tradisi yang ada di desa Penanggoan Duren, ialah proses berjalan kaki yang dilakukan oleh pihak mempelai laki-laki menuju rumah mempelai perempuan dengan membawa seserahan yang akan diberikan kepada pengantin perempuan tanpa adanya perjanjian sepihak. Berupa bahan pangan seperti beras, ayam, bumbu dapur, pohon pinang, pisang dan masih banyak lagi.
\end{abstract}

Kata Kunci : Penyajian, Musik Dalam Antar-Antaran, Desa Penanggoan Duren 


\section{Pendahuluan}

Desa penanggoan duren adalah desa yang termasuk dalam kecamatan tulung selapan, berada pada kabupaten ogan komering ilir dan terletak pada sumatra selatan. Pada setiap daerah Tentunya memiliki kebudayaan dan seni tradisi dan kearifan lokal yang dijaga dan dilestarikan keasriannya secara turuntemurun.

Adapun kesenian yang terdapat pada desa penanggoan duren kecamatan tulung selapan kabupaten ogan komerig ilir, yaitu kesenian antar-antaran. Antarantaran merupakan suatu kesenian tradisi yang ada di desa penanggoan duren, ialah proses berjalan kaki yang dilakukan oleh pihak mempelai laki-laki menuju rumah mempelai perempuan dengan membawa seserahan yang akan diberikan kepada pengantin perempuan tanpa adanya perjanjian sepihak. Berupa bahan pangan seperti beras, ayam, bumbu dapur, pohon pinang, pisang dan masih banyak lagi.

Kesenian antar-antaran ini adalah kesenian yang biasanya wajib dilakukan dalam pengiringan antarantaran pada saat pernikahan, karena sebagai simbolis dari wujud kebahagian dari sepasang pengantin untuk saling membantu, pihak laki-laki kepada perempuan dalam perlaksanaan pernikahan. Namun dibalik itu juga antar-antaran ini hanya dilakukan pada saat mempelai laki-laki dan perempuan hanya berasal dari daerah yang sama.

Berdasarkan dari data dan informasi hasil wawancara yang didapat oleh nara sumber menurut (matnasa) selaku ketua adat di desa penanggoan duren, didalam antar-antaran terdapat musik yang mengiring proses iring-iringan yaitu: kenong dan rebana yang menemani proses berjalan kaki.

Dalam penyajiannya musik antar-antaran merupakan, kesenian yang terbilang unik dan menarik untuk dijaga dan dilestarikan, karena meskipun terbilang cukup sederhana musik antar-antaran ini adalah kesenian yang sering dipakai dari dulu hingga sekarang sebagai simbolis dari adat daerah penanggoan duren yang harus dijaga sampai anak dan cucu nanti pada saat pernikahan. Adapun keunggulan dari kesenian musik antar-antaran ini yaitu kesenian ini hanya ada di desa penanngoan duren dan sampai sekarang iring-iringan atau yang biasanya disebut oleh masyarakat desa yaitu antarantaran, masih dipakai dan digunakan hingga sekarang pada saat acara pernikahan.(wawancara 23 januari 2021 pukul 19:45 WIB)

Alat musik yang terdapat dalam antar-antaran yaitu: kenong dan rebana yang termasuk dalam musik ritmis,kenong merupakan alat musik yang terbuat dari kuningan, yang berbentuk bulat menyerupai gong namun memiliki ukuran yang sedang atau pun kecil, pukulan nya terbuat dari kayu dan diujung nya dililiti oleh karet atau kain agar saat dipukul suaranya nyaring dan bulat. Sedangkan rebana adalah alat musik pukul yang dipukul menggunakan tangan yang berbentuk bulat serta terbuat dan dilapisan kulit sapi ataupun kambing.

Sejarah kenongan atau yang biasa disebut kenong di desa Penanggoan Duren sudah sering dan dari dulu digunakan oleh kakek buyut dimasyarakat desa, musik kenongan ini sangat berperan penting dan sangat berguna bagi masyarakat desa tidak hanya digunakan pada saat antar-antaran atau pernikahan namun juga digunakan untuk peringatan jam pada saat bulan puasa, karna pada saat itu masyarakat masih hidup dengan kesederhanaan dan belum mengenal alat elektronik, dengan bantuan matahari biasanya sambil menghitung untuk menunjukan pada pukul berapa maka kenong akan dibunyikan sesuai dengan jumlah jam pada saat pemukulan.(wawancara 23 januari 2021 pukul 19:45 WIB)

Peneliti menarik kesimpulan untuk tertarik melakukan penelitian agar dapat menggalih lebih jelas lagi dan akurat tentang bagaimana bentuk penyajian musik dalam antar-antaran pada acara pernikahan yang ada di desa penanggoan duren kecamatan tulung selapan kabupaten ogan komering ilir, Selain terbilang cukup unik jadi sangat disayangkan jika musik antar-antaran akan menghilang dan punah. Tujuan peneliti ingin Mengenalkan pada masyarakat luas, berusaha menjaga agar musik tradisional tidak dikalahkan oleh perkembangan zaman dan teknologi maka akan membuat rasa ketertarikan pada musik tradisional dan kesenian lokal.

Berdasarkan uraian diatas, maka peneliti tertarik untuk meneliti yang berjudul : "Penyajian Musik Antar-Antaran Pada Acara Pernikahan di Desa Penangooan Duren Kecamatan Tulung Selapan Kabupaten Ogan Komering Ilir”.

Tinjauan pustaka merupakan langkah awal untuk mengarahkan penelitian ini berupaya mencari teori-teori yang relevan dengan kajian yang hendak di bahas dengan masalah yang di rumuskan. Untuk itu penulis mencari buku-buku sumber sebagai refrensi yang dijadikan sebagian kajian teori, baik dari artikel, maupun tulisan dan hasil-hasil penelitian yang dianggap relevan dengan masalah yang akan dibahas dalam penelitian ini.

\section{Bentuk Penyajian}

Bentuk dalam kamus Besar Bahasa Indonesia (2007) dalam jurnal (Arum Purwinda Putra , Bagus Susetyo, 2012, p. 2). Mempunyai arti wujud atau rupa.

Menurut Langer dalam, (Fitri, 2015, p. 6). Bentuk adalah struktur artikulasi sebuah hasil kesatuan yang menyeluruh dari sesuatu hubungan berbagai faktor yang saling berkaitan.

\section{Musik Tradisional}

Musik tradisional adalah musik yang diciptakan dan digemari oleh masyarakat masa lalu yang sampai saat sekarang masih terus dikembangkan dan dilestarikan secara turun-temurun sebagai sarana hiburan dan identitas daerah. Perkembangan musik tradisional ini dipengaruhi oleh aktor dan seniman, jenis musik dan masyarakat luas yang mendengar dan menikmatinya. Musik daerah atau musik tradisional merupakan musik yang lahir dan berkembang dari daerah-daerah diseluruh Indonesia. Disetiap daerah meiliki ciri dan jenis musik yang berbeda-beda.(Putri, 2012, p. 319)

Menurut tumbijo 1977:13 dalam (Hendriani, 2016, p. 64). Musik tradisional adalah seni budaya yang 
sejak lama turun-temurun telah hidup dan berkembang pada daerah tertentu.

Berdasarkan uraian diatas, dapat disimpulkan musik tradisional adalah merupakan musik yang lahir dan berkembang pada suatu daerah, Yang pada setiap daerahnya memiliki ciri khas masing-masing dan tentunya musik itu akan dijaga dan di turun-temurunkan.

Berdasarkan uraian diatas, dapat disimpulkan bahwasanya bentuk penyajian merupakan suatu bentuk wujud ungkapan hati dan perasaan oleh seniman kepada para penikmat dalam karya seni yang dibuat, yang memiliki ungkapan perasaan yang khusus untuk disampaikan baik itu berupa keindahan, emosional, nilai, rasa yang diberikan kepada orang yang menyasikan penyajian tersebut.

\section{Alat Musik Antar-antaran}

\section{Kenong}

Kenong/canang adalah alat musik pukul tradisional yang terdapat dalam kelompok masyarakat aceh menyebutnya "canang Trieng" di gayo di sebut "Teganing", di Tamiang di sebut "kecapi" di alas disebut dengan "kecapi olah".(A., 2010, p. 46)

Kenongan atau sering disebut dengan kata lain canang adalah salah satu alat musik tradisional Aceh yang mempunyai arti yang berbeda pada setiap daerah di Aceh. Secara sepintas lalu ditafsirkan sebagai alat musik yang dipukul, terbuat dari kuningan menyerupai gongHanya saja cananglebih kecil ukuran nya dibandingkan dengan gong. (Nurul vitria, ahmad syai, aida fitri, 2017, p. 344)

Menurut Matnasa kenong merupakan sejenis alat musik pukul yang terbuat dari batang logam atau kuningan. Dalam acara antar-antaran pada masyarakat desa penanggoan duren ini, kenong memang sudah sering digunakan sejak dahulu sebagai media musik pengiring pada antar-antaran tersebut diiring dengan musik rebana juga, sudah menjadi tradisi yang memang sudah ada sejak dahulu karna kenong sangat berperan penting di desa penanggoan duren ini. (wawancara 23 Januari 2021 pukul 19:45 WIB ).

Berdasarkan uraian diatas, dapat disimpulkan kenongan adalah sejenis alat pukul yang terbuat dari logam dan kuningan yang memiliki nama yang berbedabeda diSetiap daerah nya.

\section{Rebana}

Menurut mushofa dalam (Putri L. I., 2017)Rebana adalah alat musik yang cara memainkannya dengan cara dipukul menggunakan tangan maupun jari jemari tangan. Kemudian pengertian lain dari rebana adalah sejenis gendang/kendang yang berbentuk bundar dan pipih yang menjadi ciri khas alat musik melayu.

Berdasarkan uraian di atas dapat disimpulkan bahwa rebana adalah sejenis alat musik pukul yang di pukul menggunakan tangan atau jari yang berbentuk seperti kendang menjadi alat musik ciri khas melayu.

\section{METODE PENELITIAN}

Kata 'metode' dan 'metodologi' sering dicampuradukkan dan disamakan. Padahal keduanya memiliki arti yang berbeda. Kata 'metodelogi' berasal dari yunani 'methologia' yang berasal 'teknik' atau 'prosedur'Metodologi sendiri merujuk kepada alur pemikiran umum atau menyeluruh (general logic) dan gagasan teoritis (theoretic perspectives) suatu penelitian.(Semiawan, 2010, p. 1)

$$
\text { Menurut Denzin dan lincoln }
$$

dalam,(Hendiansyah, 2010, p. 7). Penelitian kualitatif lebih ditunjukan untuk mencapai pemahaman mendalam mengenai organisasi atau peristiwa khusus daripada mendeskripsikan bagian permukaan dari sampel besar dari sebuah populasi.

Menurut moleong dalam, (Herdiansyah, metodologi penelitian kualitatif untuk ilmu-ilmu sosial, 2010, p. 9). Penelitian kualitatif adalah penelitian yang bermaksud untuk memahami fenomena tentang apa yang dialami oleh subjek penelitian, misalnya perilaku, persepsi, motivasi, tindakan, dan lain sebagainya.

Berdasarkan uraian diatas, peneliti menyimpulkan metode penelitian kualitatif adalah penelitian yang menerapkan pada analisis dari proses berpikir yang menekanka berkaitan dengan penomena alami. Untuk mencapai pemahaman yang mendalam, untuk mendapatkan data dan kebenaran pada suatu peristiwa khusus yang terjadi. Oleh karena itu pengumpulan data dilakukan dengan tahapan observasi, wawancara, observasi, dan dokumentasi, selanjutnya data yang sudah dikumpulkan dan analisis dipaparkan secara deskriptif.

\section{Pembahasan}

Hasil penelitian merupakan suatu penjabaran atau jawaban dari permasalahan pada penelitian yang sudah dilakukan, adapun penjelasan tentang bagaimana penelitian dan hasil penelitian ini didapatkan melalui penjabaran yang diuraikan.

\section{Penyajian Antar-antaran}

Wawancara pada (27 april 2021 pukul 13:45 WIB) oleh Matnasa. Antar-antaran adalah kesenian yang berada pada desa penanggoan duren yang sampai saat sekarang masih dipakai pada saat acara pernikahan, Antar-antaran sudah termasuk tradisi atau adat yang ada pada desa penanggoan duren pada sejak masa leluhur atau nenek moyang, yang hingga sekarang masih dijaga dan dilestarikan.

Dalam setiap daerah tentunya memiliki adat dan istiadat dalam suatu kebiasan yang sudah sejak dari dulu diwariskan dan dijaga begitu juga di desa penanggoan duren terdapat yaitu istilah yang biasa di sebut antarantaran.

Antar-antaran merupakan suatu proses berjalan kaki yang dilakukan oleh pihak keluarga mempelai laki-laki menuju rumah mempelai perempuan dalam kegiatan ini biasanya dilakukan pada saat mempelai laki-laki dan perempuan sama-sama berasal dari satu daerah atau tempat yang sama. Antar-antaran ini merupakan simbol wujud dari kebahagian dari kedua pasang pengantin bahwa masyarakat desa penanggoan duren sangat 
memiliki nilai tolong menolong dan jiwa sosial yang tinggi.

\section{Penyajian Musik Antar-antaran}

Musik antar-antaran adalah musik tradisional yang diiring oleh alat musik rebana dan kennong alat musik ini termasuk golongan musik ritmis. Adapun penyajian nya sebelum acara antar-antaran berlangsung ibu-ibu yang akan memainkan rebana akan bersiap terlebih dahulu. Menurut ibu Layli (wawancara pada tanggal 27 april 2021) jumlah pemain dari rebana ini terdapat 13 orang yang beranggotakan perempuan semua yang memainkan rebana ini pada saat antar-antaran yang diketuai oleh ibu Mastina. Pada saat antar-antaran berlangsung rebana akan mengiringi proses perjalanan kaki sebanggai musik penggiring yang bertujuan untuk menyemarakan proses antar-antaran.

\section{Penyajian Instrumen Dalam Musik Antar-Antaran}

a) Lagu

Dalam penyajian nya menurut ibu yanis,(wawancara 23 mei 2021) musik rebana pada saat mengiring antar-antaran membawakan beberapa lagu mulai sebelum perjalanan saat sangat perjalanan dan hingga sampai ditujuan atau rumah mempelai laki-laki. Pada saat sebelum perjalan masih berada pada rumah mempelai perempuan grup rebana arahman biasa menyanyikan lagu shalawat-shalawat seperti: lagu perdamaian, jilbab putih, nabi muhammad mataharinya dunia, dan yang terahir atau sering dinyanyikan setelah sampai tujuan yaitu lagu slamat datang lagu selamat datang adalah lagu pamungkas yang dinyanyikan apabila antar-antaran akan selesai atau rombongan telah sampai ditujuan kediaman pihak mempelai perempuan.

\section{b) Syair/lirik}

Berikut berapa lagu atau syair yang sering dinyanyikan pada saat proses antar-antaran dilakukan biasanya para kelompok rebana akan menyanyikan sholawat-sholat sebelum tiba dirumah mempelai pengantin perempuan.

Setelah ingin sampai dirumah mempelai perempuan grup rebana ar-rahaman akan menyanyikan lagu selamat datang guna untuk memberi tanda bahwa rombongan sudah sampai dan menyambut para tamu undangan yang juga hadir dikediaman mempelai perempuan berikut lirik dari lagu selamat datang:

\section{Selamat datang}

Selamat datang tamu sekalian ucapkan

Kepada bapak ibu dan handwautan

Yang berbudi telah sudi menghadiri

Perayaan hari ini perayaan

Perkawinan......

Intro:

Selamat datang tamu sekalian ucapkan

Kepada bapak ibu dan hanwautan

Yang berbudi telah sudi menghadiri

Perayaan hari ini

Perayaan hari ini perayaan perkawinan $2 X$

\section{Penyajian Alat Musik Dalam Antar-Antaran} a) Kenong

Menurut bapak Sopiyan pada wawancara pada 23 april 2021, alat musik yang digunakan dalam pertunjukan antar-antaran pengantin di desa penanggoan duren menggunakan alat musik kenong dan rebana.

\section{b) Rebana}

Menurut bu Yanis rebana adalah alat musik pukul yang terbuat dari keramik dan dilapisi oleh kullit kambing,yang dipukul menggunakan tangan dan memiliki berbagai macam tabuhan

\section{Teknik Memainkan}

\section{Kenong}

Cara memainkan kenong memiki teknik tangan dengan memegang tali dengan menggunakan tangan kiri dan tangan kanan memegang pemukul,posisi tangan memegang bagian ujung kayu dan pada salah satu ujungnya dilapisi dengan kain bisa juga dengan karet agar suara kenong terdengar dengan bulat. lalu di pukul sesuai irama, atau nada yang biasa dibunyikan..

\section{Rebana}

Teknik dalam memainkan rebana memiliki 3 bagian:

a. Teknik tangan

Bagaimana cara memegang rebana cara memegang rebana agar tidak jatuh dan mantap yaitu, tangan kiri berpungsi memegang bagian samping dari sisi rebana dengan 4 jari didepan lalu ibu jari berada dibelakang.Sedangkan tangan kanan berpungsi untuk menepuk atau memukul bagian depan sisi rebana yang terbalut kulit kambing.

b. Tenaga

Dalam memainkan rebana tentunya harus memiliki tenaga yang kuat dan tahan lama ini tentunya akan mempengaruhi suara dan pukulan jika kita memukul rebana dengan tenaga yang lemah maka akan mempengaruhi suara atau bunyi dari rebana tersebut.

c. Pukulan

Memukul rebana harus dengan cara yang benar supaya tangan tidak sakit jika memukul rebana agar tangan tidak sakit biasanya dengan menggunakan samping dari telapak tangan bukan di tengah telapak tangan.

\section{Pola Tabuhan dan Penotasian}

Pola Tabuhan ialah istilah yang digunakan untuk menyebutkan sejenis pukulan atau tabuhan sama halnya dengan memainkan dengan cara dipukul.

Menurut ibu Yanis wawancara pada 2 mei 2021, jumlah pola tabuhan musik rebanan yang dikembangkan oleh kelompok arahman pada pertunjukan antar-antaran ada 4 pola tabuhan dipakai yaitu:

1. Pola tabuhan 1

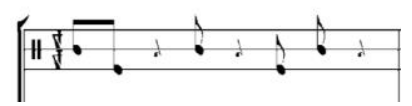

2. Pola tabuhan ningkat 2

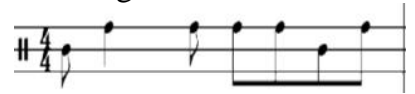


3. Pola tabuhan ningkat 3

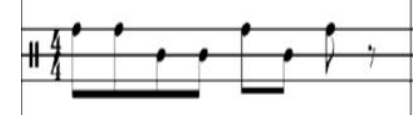

4. Pola tabuhan ningkat 4

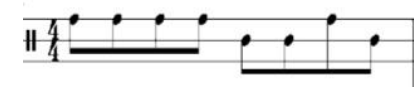

\section{Notasi Tabuhan Rebana}

Didalam musik antar- antaran terdapat alat musik yang mengiringinya yaitu rebana dan kenong sebagai alat musik ritmis yang berpungsi untuk mengiring pada saat proses perjalanan antar-antaran grup rebana akan berjalan kaki menuju rumah mempelai pengantin perempuan, didalam alat musik rebana terdapat pola tabuhan yang dimainkan pada saat antar-antaran berlangsung yaitu pola tabuhan ngumak atau 1, dan pola tabuhan 2,3, dan 4. Sebelum proses perjalan berlangsung grup rebana ar-rahman akan menyanyikan beberapa lagu shalawat-shalawat yang dinyanyikan namun dibawah ini ada satu lagu yang akan dibawakan pada saat proses antar-antaran berlangsung pola tabuhan rebana dalam lagu selamat datang.

Setelah perjalanan akan sampai menuju rumah mempelai perempuan grup ar-arahman akan menyanyikan lagu selamat datang yaitu, di mulai dengan pola tabuhan ngumak atau 1,dan setelah itu dilanjutkan dengan pola tabuhan 2 dan 3 disusul dengan pola tabuhan ke 4 hingga selesai sesuai atau penenutup.
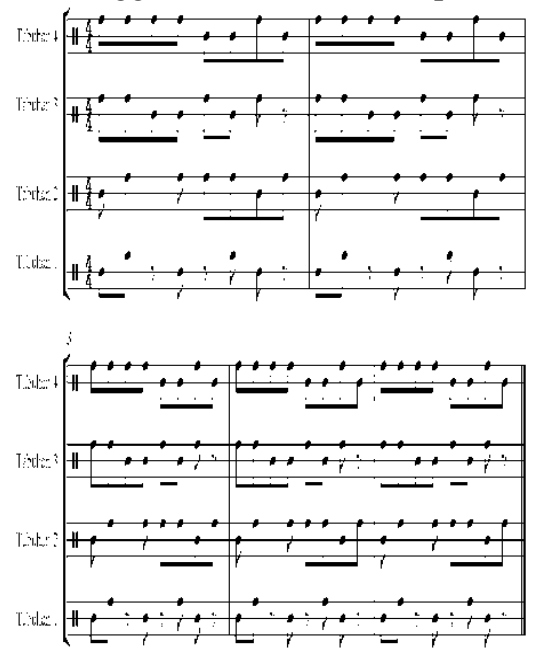

\section{Pola notasi tabauhan kenong}

Dibawah ini merupakan pola tabuhan kenong pada saat antar-antaran berlangsung dengan diiringi alat musik rebana kenong juga akan mengiringi proses antar-antara yang berpungsi sebagai penjuluk dari antar-antaran dan mengiring proses perjalanan kaki agar antar-antaran akan lebih semarak atau meriah, ketika romongan mulai beranjak menuju rumah mempelai pengantin perempuan kenong akan berada didepan rombongan serta bersama grup rebana dengan mengiringi proses berjalan kaki dengan membawa berupa barang sesarahan yang kan di berikan kepada mempelai pengantin perempuan.
Kenong dimainkan oleh satu orang saja karna kenong hanya digunakan satu alat saja sebagai media pembantu mengiringi proses antar-antaran tersebut, selain itu juga dimasyarakat desa kenong juga digunakan sebagai alat komunikasi atau petanda sebelum dimulainya antar-antaran kenong akan dibunyikan untuk memberi tanda bahwa pada hari itu ada masyarakat yang akan melakukan antar-antaran tentunya sebelum itu pihak keluarga sudah mengundang masyarakat kalau akan melakukan pernikahan.Berikut pola tabuhan dari kenong pada saat mengiri antar-antaran:

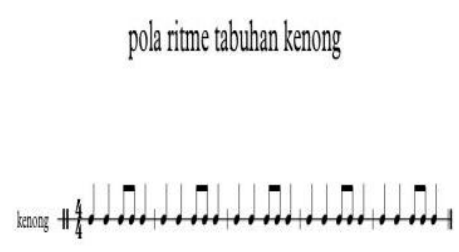

\section{Peristiwa Dalam Penyajian Musik Antar-Antaran Pada Acara Pernikahan.}

Di dalam penyajian antar-antaran dimulai ada prosesi-prosesi yang dilakukan oleh masyarakat didesa penanggoan duren yaitu:

1.) Masyarakat akan berkumpul dirumah kediaman mempelai pengantin laki-laki dengan membawa seserahan yang akan diberikan kepada mempelai pengantin perempuan, sebelum antar-antaran di mulai masyarakat atau pihak-pihak keluarga yang bersangkutan dalam pelaksanaan antar-antaran tersebut akan menyiapkan apa saja yang akan dibawa dan diberikan nanti nya.

2.) Selanjutnya sebelum menuju rumah mempelai pengantin perempuan grup rebana ar-rahman akan menghibur masyarakat yang ada disitu dengan memainkan beberapa lagu shalawat-salawat seperti lagu perdamaian, jilbab putih, sembari menunggu persiapan yang sedang dilakukan oleh pihak mempelai pengantin laki-laki.

3.) Selanjutnya ada kenongan alat musik pukul yang sering digunakan sebagai media simbol pemanggil masyarakat dari rumah kerumah untuk memberi tanda bahwa ada masyarakat yang mengadakan antarantaran jadi selain digunakan sebagai alat musik pengiring rebana kenongan ini juga digunakan sebagai alat pemanggil oleh masyarakat desa penanggoan duren.

4.) Setelah persiapan sudah selesai atau lengkap rombongan akan bersiap-siap menuju rumah mempelai perempuan dengan berjalan kaki dengan membawa seserahan yang akan diberikan. Rebana dan kenong pun adalah alat musik yang digunakan dalam proses antar-antaran ini sebagai media pertunjukan dan penghibur untuk memeriahkan seserahan tersebut, didalam proses perjalanan kaki ini grup rebana ar-rahman akan menyanjikan lagu selamat datang sebagai lagu penyambutan kepada 
para tamu yang telah terdahulu sampai kepada rumah pihak mempelai perempuan.

5.) setelah sampai dirumah mempelai perempuan rombongan akan disambut dan dipersilakan duduk dan menikmati hidangan yang telah diberikan.

6.) Terahir penutup setelah selesai menikmati hidangan pihak mempelai pengantin laki-laki akan memberikan seserahan tersebut kepada pihak mempelai perempuan sebagai simbolis rasa bahagia dan tolong menolong dalam pelaksanaan dalam pernikahan, tentunya antar-antaran ini dilakukan sesuda prosesi lamaran yang biasanya antar-antaran ini dilakukan sebelum hari resepsi pernikahan tersebut.

\section{Kesimpulan}

Berdasarkan pembahasan bab-bab sebelumya dan hasil penelitian tentang "bentuk penyajian musik dalam antar-antaran di desa penanggoan duren kecamatan tulung selapan kabupaten ogan komering ilir" dengan metode deskriptif kualitatif, maka dapat disimpulkan, yaitu sebagai berikut:

1) Didalam desa penanggoan duren terdapat sebuah kesenian tradisi atau adat yang di gunakan pada saat acara menjelang pernikahan yaitu yang disebut antar-antaran. yang dalam istilah lain sering disebut arak-arakan merupakan suatu rangkai prosesi dimana pihak mempelai pengantin laki-laki akan memberikan seserahan berupa bantuan kebutuhan primer dan sekunder yang dilakukan pada saat sebelum hari resepsi tanpa keputusan sepihak artinya dilakukan dengan niat tulus ingin membantu.diadakan yaitu sebagai bentuk rasa tolong menolong kepedulian bersama dalam melakukan suatu acara yang akan diadakan.

2) Bentuk penyajian musik antar-antaran diiringi dengan alat musik rebana dan kenong, kenong merupakan alat musik sejenis gong kecil yang terbuat dari kuningan dan pemukulannya terbuat dari kayu yang salah satu ujungnya dilapisi dengan kain atau karet,cara membunyikan ialah dengan tangan kiri memegang tali dari bagian kenong dan tangan kanan memegang pemukul dan dipukulkan sesuai irama dan bunyi. Sedangkan rebana adalan alat musik yang terbuat dari tanah dan kramik yang dilapisi oleh kulit kambing dan sapi. Cara membunyikan dengan cara memegang tangan kiri bertugas menepuk pada bagian depan atau pada sisi kulit rebana.

3) Penyajian musik rebana ini hanya dilakukan apabila mempelai pengantin laki-laki dan perempuan hanya berasal dari daerah yang sama hal ini dikarnakan proses jalan kaki yang cukup jauh, jika berasal dari daerah yang berberbeda mempelai laki 46 nya akan memberikan seserahan namun ticun un. gan antar-antaran.

Berdasarkan hasil penelitian tentang "bentuk penyajian musik dalam antar-antaran didesa penanggoan duren kecamatan tulung selapan kabupaten ogan komering ilir". Dengan menggunakan metode deskriptif kualitatif maka saran yang dapat diberikan oleh peneliti kepada pihak-pihak yang terlibat didalamya yaitu sebagai berikut:

1. Pemerintah daerah setempat khususnya kepada badan kebudayaan dan dinas pariwisata agar lebih memperbanyak lagi sumber-sumber tertulis yang lebih lengkap tentang kebudayaan didaerah setempat agar dapat dijadikan sumber referensi dalam hal ini khusus nya didesa penanggoan duren kecamatan tulung selapan kabupaten ogan komering ilir.

2. Kepada generasi muda mudi yang ada didesa penanggoan duren agar terus menjaga kebudayaan dan seni tradisi yang ada di daerah setempat agar bisa dilihat dan dinikmati oleh generasi selanjutnya ciri khas daerah akan tetap ada hingga pada masa berikutnya.

3. Kepada masyarakat desa penanggoan duren kecamatan tulung selapan kabupaten ogan komering ilir. Agar dapat menghargai kesenian warisan budaya nenek moyang yang terdaulu khususnya yaitu bentuk penyajian musik dalam antar-antaran yang harus tetap dijaga dan dilestarikan.

4. Kepada tokoh-tokoh adat di desa penanggoan duren kecamatan tulung selapan kabupaten ogan komering ilir agar meninjau lebih lanjut segala aspek permasalahan, sehingga dapat menambah pengetahuan bagi peneliti selanjutnya dan dapat memperkaya keanekaragaman budaya nusantara dan keraifan lokal daerah setempat

\section{Daftar Pustaka}

A., H. R. (2010). Mengenal Alat Musik Tradisional. Bogor: Quandra.

Ardiansyah.(2020). Pelestarian Situs Megalitik Sebagai Objek Wisata Terpadu Di Kabupaten Lahat, Sumatera Selatanhistorical Studies Journal 112

Darmawan, R. (2013). Peran Battra Dalam Penunukanngobatan Tradisional Pada Komunitas Dayak Agabag Di Kecamatan Lumbis Kabupaten. E-Jurnal Sosiatri-Sosiologi .

Ermitati. (2014). Pengungkapan Budaya Suku Anak Dalam Melalui Kosakata Bahasa Kubu. Kandai, 154.

Fitri, M. (2015). Bentuk Penyajian Tari Inen Mayak Pukes Pada Masyarakat Aceh Tengah . E- Jurnal Seni Tari Fbs Unimed, 6.

Fitria, R. (2012). Proses Pembelajaran Dalam Setting Inklusi Di Sekolah Dasar. Jurnal Ilmiah Pendidikan Khusus, 1, 4.

Gora, R. (2019). Riset Kualitatif Public Relation. Surabaya: Cv Jaka Publishing Surabaya.

Hardianas, D. (2017). Sejarah Kebudayaan Lokal Pada Candi Borobudur Sebagai Sumber Pembelajaran Sejarah. Palembang: Universitas Pgri Palembang.

Herdiansyah, H. (2010). Metodologi Penelitian Kualitatif Untuk Ilmu-Ilmu Sosial. Jakarta Selatan: Salemba Humanika. 
Juarsih, D. D. (2014). Kegiatan Pembelajaran Yang Mendidik. Jakarta: Rineka Cipta.

Khoiri. (2017). Tahap-Tahap Penelitian Kualitatif. Yogyakarta: Balai Pustaka.

Mamik. (2015). Metodologi Kualitatif .Sidoharjo: Zifatama

Maryaeni. (2012). Metodologi Penelitian Kebudayaan. Jakarta: Pt Bumi Aksara.

Matnasa. (23 Februari 2021). Wawancara.

Mekarisce, A. A. (2020). Teknik Pemeriksaan Keabsahan Data Pada Penelitian Kualitatif Di Bidang Kesehatan Masyarakat. Jurnal Ilmiah Kesehatan Mayarakat, 12, 4.

Kabupaten Polewi Mandar. Jurnal Naharawinurdien, 5.

Nurdin, M. \&. (2013). Kehidupan Keagamaan Suku Anak Dalam Didusun Senami Iii Desa Jebak Kabupaten Batang Hari Jambi. Kontekstualita, 152-153.

Nurul Vitria, Ahmad Syai, Aida Fitri. (2017). Fungsi Dan Bentuk Alat Penyajian Alat Musik Canang Dalam Prosesi Adat Perkawinan 